\title{
Early-life exposures to environmental tobacco smoke and indoor air pollution in the Drakenstein Child Health Study: Impact on child health
}

Lower respiratory tract infections (LRTIs) are the leading cause of childhood morbidity and mortality in South Africa (SA). Despite sustained efforts to decrease this, including better access to vaccination and strengthening of primary healthcare services, childhood LRTIs continue to impact significantly on child health. ${ }^{[1,2]}$

SA, a middle-income country, has undergone much social and political change in the past two decades, resulting in urban migration and the mushrooming of peri-urban communities with subsequent health, education and environmental challenges. ${ }^{[3]}$ Despite an increase in electrification, many households continue to rely on alternative fuel sources for cooking and heating. ${ }^{[4]}$ Burning of alternative fuels (such as paraffin, wood, coal and other biomass substances), often in inadequately ventilated homes, contributes to indoor air pollution, a recognised risk factor for respiratory disease ${ }^{[5]}$ Further, environmental tobacco smoke exposure continues to be problematic despite anti-smoking legislation. ${ }^{[6]}$

The Drakenstein Child Health Study (DCHS), an SA birth cohort study of 1000 mother-child pairs, longitudinally investigates the epidemiology, risk factors, aetiology and long-term outcome of childhood diseases, including respiratory illnesses. ${ }^{[7]}$ The study site is in a peri-urban, poor socioeconomic community in the Drakenstein subdistrict, $50 \mathrm{~km}$ from Cape Town. Pregnant women were enrolled from two public primary healthcare clinics, Mbekweni (serving a predominantly black African population) and Newman (predominantly mixed-ancestry population), and all deliveries occurred at Paarl Hospital. Children are followed up until at least 5 years of age.

The impact of indoor air pollution (IAP) and environmental tobacco smoke (ETS) exposure on child health was investigated in the DCHS. To measure exposures comprehensively, two home visits, one in the antenatal period (third trimester) and the second postnatally (between 4 and 6 months of the infant's life), were conducted to assess the home environment and to measure the most common indoor air pollutants and byproducts of combustion. Devices placed in participants' homes measured exposure to particulate matter $\left(\mathrm{PM}_{10}\right)$, carbon monoxide $(\mathrm{CO})$, nitrogen dioxide $\left(\mathrm{NO}_{2}\right)$, sulphur dioxide $\left(\mathrm{SO}_{2}\right)$ and volatile organic compounds (VOCs). ${ }^{[8]}$ Measurements of IAP were obtained from 863 antenatal and 723 postnatal home visits, providing important SA data on IAP and potential sources of pollution. Measured benzene (VOC) levels were significantly above acceptable SA ambient standards, ${ }^{[9]}$ and together with $\mathrm{CO}$ and $\mathrm{NO}_{2}$, increased levels were associated with fossil fuel use. ${ }^{[8]}$

Tobacco smoking by pregnant women is often under-reported globally, although household ETS exposure may be high. ${ }^{[10,11]}$ In the DCHS, urine cotinine measures were used to validate maternal selfreported smoking and exposure. ${ }^{[12]}$ Tobacco smoking and exposure was found to be highly prevalent, with a smoking prevalence of $>50 \%$ in mixed-ancestry mothers. Alarmingly, $18 \%$ of infants were born with urine cotinine levels in keeping with active smoking, while a further $30 \%$ had levels indicating passive smoke exposure. ${ }^{[12]}$ The impact of the exposures on birth outcomes was significant, with antenatal maternal smoking associated with lower birth weight. ${ }^{[12]}$
The timing of environmental exposures on the subsequent development of LRTI in infancy has not been well described. Most interestingly, we found that antenatal exposures were the main risk factors associated with LRTI, with maternal smoking in pregnancy or $\mathrm{PM}_{10}$ exposure most strongly associated with LRTI. Further, maternal smoking in pregnancy or antenatal passive smoke or $\mathrm{PM}_{10}$ exposure was associated with wheezing in infants. ${ }^{[13]}$ Interestingly, toluene, a volatile organic compound, was a novel exposure associated with severe LRTI requiring hospitalisation. ${ }^{[13]}$

Environmental exposures therefore had a substantial impact on child health and on LRTI. The effect on LRTI of antenatal compared with postnatal exposure suggests an in utero developmental lung effect. This study highlights antenatal and early life as a critical period for lung development. Urgent and effective smoking cessation programmes as well as public health interventions focusing on IAP are required. Woman of childbearing age, pregnant women and children in poor communities represent vulnerable populations at risk for long-term health effects of these exposures. Early-life LRTI and environmental exposures have increasingly been associated with the development of chronic obstructive pulmonary disease in adulthood. Further longitudinal study of this cohort will provide important information on the long-term respiratory outcomes.

Acknowledgements. We thank the study and clinical staff at Paarl Hospital and Mbekweni and Newman clinics, in particular the fieldworker teams, SGS Environmental Services for supporting this project, and the participants and their families.

Funding. This study was funded by the Bill \& Melinda Gates Foundation (OPP1017641), Discovery Foundation, a South African Thoracic Society AstraZeneca Respiratory Fellowship, the National Research Foundation, SA, CIDRI Clinical Fellowship and the South African Medical Research Council.

\section{A Vanker}

Department of Paediatrics and Child Health, Red Cross War Memorial Children's Hospital, Cape Town, South Africa; and South African Medical Research Council Unit on Child and Adolescent Health, University of Cape Town, South Africa aneesa.vanker@uct.ac.za

\section{R P Gie}

Department of Paediatrics and Child Health, Tygerberg Children's Hospital and Faculty of Medicine and Health Sciences, Stellenbosch University, Cape Town, South Africa
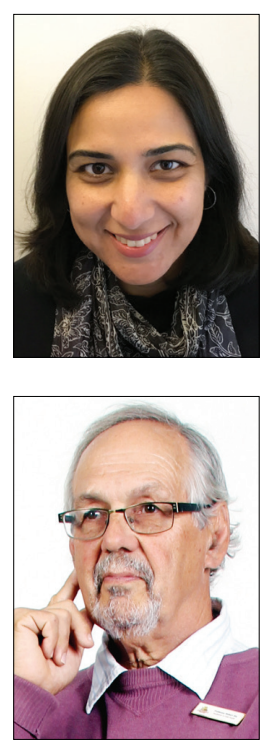


\section{H J Zar}

Department of Paediatrics and Child Health, Red Cross War Memorial Children's Hospital, Cape Town, South Africa; and South African Medical Research Council Unit on Child and Adolescent Health, University of Cape Town, South Africa

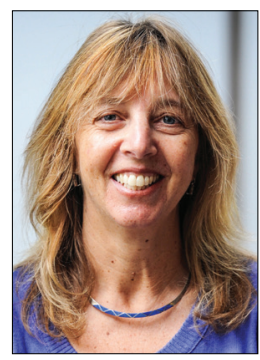

1. Rudan I, O'Brien KL, Nair H, et al. Epidemiology and etiology of childhood pneumonia in 2010 for 192 countries. J Global Health 2013;3(1):10401. https://doi.org/10.7189/jogh.03.010401

2. Zar HJ, Barnett W, Myer L, Nicol MP. Childhood pneumonia - the Drakenstein Child Health Study. S Afr Med J 2016;106(7):642-643. https://doi.org/10.7196/SAMJ.2016.v106i7.11108.

3. Statistics South Africa. The South African MPI: Creating a Multidimensional Poverty Index Using Census Data. Pretoria: Stats SA, 2014. http://www.statssa.gov.za/?page id=1854\&PPN=Report-03-10-08 (accessed 6 December 2017).

4. Statistics South Africa. General Household Survey 2013. Pretoria: Stats SA, 2014. http://www.statssa. gov.za/publications/P0318/P03182013.pdf (accessed 6 December 2017).

5. Gordon SB, Bruce NG, Grigg J, et al. Respiratory risks from household air pollution in low and middle income countries. Lancet Respir Med 2014;2(10):823-860. https://doi.org/10.1016/S22132600(14)70168-7
6. Reddy P, Zuma K, Shisana O, Kim J, Sewpaul R. Prevalence of tobacco use among adults in South Africa: Results from the first South African National Health and Nutrition Examination Survey. S Afr Med J 2015;105(8):648-655. https://doi.org/10.7196/SAMJnew.7932

7. Zar HJ, Barnett W, Myer L, Stein DJ, Nicol MP. Investigating the early-life determinants of illness in Africa: The Drakenstein Child Health Study. Thorax 2015;70(6):592-594. https://doi.org/10.1136/ thoraxjnl-2014-206242

8. Vanker A, Barnett W, Nduru PM, Gie RP, Sly PD, Zar HJ. Home environment and indoor air pollution exposure in an African birth cohort study. Sci Total Environ 2015;536(1 Dec):362-367. https://doi. org/10.1016/j.scitotenv.2015.06.136

9. Government Gazette, Republic of South Africa. National Ambient Air Quality Standards. Pretoria, 2009. https://www.gov.za/documents/national-environmental-management-air-quality-act-nationalambient-air-quality-standards (accessed 6 December 2017).

10. Caleyachetty R, Tait CA, Kengne AP, Corvalan C, Uauy R, Echouffo-Tcheugui JB. Tobacco use in pregnant women: Analysis of data from Demographic and Health Surveys from 54 low-income and middle-income countries. Lancet Global Health 2014;2(9):e513-e520. https://doi.org/10.1016/S2214109X(14)70283-9

11. Öberg M, Jaakkola MS, Woodward A, Peruga A, Prüss-Ustün A. Worldwide burden of disease from exposure to second-hand smoke: A retrospective analysis of data from 192 countries. Lancet 2011;377(9760):139-146. https://doi.org/10.1016/S0140-6736(10)61388-8

12. Vanker A, Barnett W, Brittain K, et al. Antenatal and early life tobacco smoke exposure in an African birth cohort study. Int J Tuberc Lung Dis 2016;20(6):729-737. https://doi.org/10.5588/ijtld.15.0697

13. Vanker A, Barnett W, Workman L, et al. Early-life exposure to indoor air pollution or tobacco smoke . Vanker A, Barnett $\mathrm{W}$, Workman $\mathrm{L}$, et al. Early-life exposure to indoor air pollution or tobacco smoke
and lower respiratory tract illness and wheezing in African infants: A longitudinal birth cohort study. and lower respiratory tract illness and wheezing in African infants: A longitudinal birth col
Lancet Planet Health 2017;1(8):e328-e336. https://doi.org/10.1016/S2542-5196(17)30134-1

S Afr Med J 2018;108(2):71-72. DOI:10.7196/SAMJ.2018.v108i2.13088 